\title{
WILEY-VCH
}

\section{Untangling Cooperative Effects of Pyridinic and Graphitic Nitrogen Sites at Metal-Free N-Doped Carbon Electrocatalysts for the Oxygen Reduction Reaction}

\author{
James A. Behan, ${ }^{a}$ Eric Mates-Torres, ${ }^{a}{ }^{1}$ Serban N. Stamatin,,${ }^{a, b}$ Carlota Domínguez, ${ }^{a}$ \\ Alessandro Iannaci, ${ }^{a}$ Karsten Fleischer, ${ }^{c}$ Md. Khairul Hoque, ${ }^{a}$ Tatiana S. Perova, ${ }^{d}$ Max \\ García-Melchor $^{a} *$ and Paula E. Colavita ${ }^{a, *}$
}

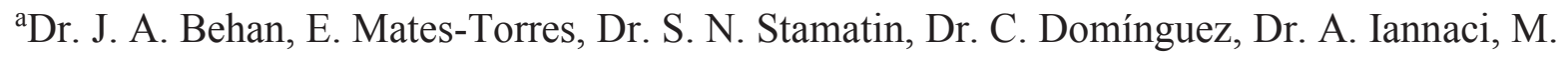
K. Hoque, Prof. M. García-Melchor, Prof. P. E. Colavita School of Chemistry, CRANN and AMBER Research Centres, Trinity College Dublin, Dublin 2, Ireland.

E-mail: garciamm@tcd.ie; colavitp@,tcd.ie

${ }^{b}$ Dr. S. N. Stamatin

Faculty of Physics, 3Nano-SAE Research Centre

University of Bucharest

405 Atomistilor Str., Bucharest-Magurele

077125, Romania.

${ }^{\mathrm{c}}$ Dr. K. Fleischer

School of Physics, CRANN and AMBER Research Centres, Trinity College Dublin,

Dublin 2, Ireland.

${ }^{\text {dProf. T.S. Perova }}$

Department of Electronic and Electrical Engineering, Trinity College Dublin, Dublin 2, Ireland

Keywords: N-doped carbon, oxygen reduction reaction, electrocatalysis, density functional theory, synergistic. 


\title{
WILEY-VCH
}

\begin{abstract}
Metal-free carbon electrodes with well-defined composition and smooth topography were prepared via sputter deposition followed by thermal treatment with inert and reactive gases. XPS and Raman spectroscopies show that three carbons of similar N/C content that differ in Nsite composition were thus prepared: an electrode consisting of almost exclusively graphitic-N $\left(\mathrm{N}_{\mathrm{G}}\right)$, an electrode with predominantly pyridinic-N $\left(\mathrm{N}_{\mathrm{P}}\right)$ and one with ca. 1:1 $\mathrm{N}_{\mathrm{G}}: \mathrm{N}_{\mathrm{P}}$ composition. These materials were used as model systems to investigate activity of N-doped carbons in the oxygen reduction reaction (ORR) using voltammetry. Results show that selectivity towards 4e-reduction of $\mathrm{O}_{2}$ is strongly influenced by the $\mathrm{N}_{\mathrm{G}} / \mathrm{N}_{\mathrm{P}}$ site composition, with the material possessing nearly uniform $\mathrm{N}_{\mathrm{G}} / \mathrm{N}_{\mathrm{P}}$ composition being the only one yielding a 4e-reduction. Computational studies on model graphene clusters were carried out to elucidate the effect of $\mathrm{N}$-site homogeneity on the reaction pathway. Calculations show that for pure $\mathrm{N}_{\mathrm{G}^{-}}$ doping or $\mathrm{N}_{\mathrm{P}}$-doping of model graphene clusters, adsorption of hydroperoxide and hydroperoxyl radical intermediates, respectively, is weak thus favoring desorption prior to complete 4e-reduction to hydroxide. Clusters with mixed $\mathrm{N}_{\mathrm{G}} / \mathrm{N}_{P}$ sites display synergistic effects, suggesting that co-presence of these sites improves activity and selectivity by achieving high theoretical reduction potentials while facilitating retention of intermediates.
\end{abstract}




\section{WILEY-VCH}

\section{Introduction}

Nitrogen-doped carbon nanomaterials have been under intense study over the previous decade due to their activity in metal-free electrocatalysis of the oxygen reduction reaction (ORR) ${ }^{[1-3]}$ a cathodic process that is critical to improving the efficiency of commercial fuel cell devices based on oxygen electrochemistry. ${ }^{[4-7]}$ Substantial efforts have been devoted to the fundamental understanding of the role of $\mathrm{N}$-sites by means of experimental and theoretical methods. ${ }^{[8-13]}$ This is a significant challenge, as N-doped nanocarbons typically contain a mix of different nitrogen moieties, including so-called substitutional or 'graphitic' $\mathrm{N}$ sites $\left(\mathrm{N}_{\mathrm{G}}\right)$ and pyridinic- $\mathrm{N}$ $\left(\mathrm{N}_{\mathrm{P}}\right)$ at edge sites and vacancies within the scaffold. It is therefore difficult to directly attribute the observed ORR activity of N-doped carbon electrocatalysts to specific active sites.

The ORR is a complex process involving multiple electron and proton transfers that has generated an intense debate on the nature of active sites on N-doped carbon nanomaterials. ${ }^{[5,9}$, ${ }^{11-21]}$ However, researchers have made significant progress in understanding the electrocatalytic behavior of N-doped carbon nanomaterials from fundamental structure-activity studies on welldefined carbon model systems. ${ }^{[22]}$ For example, Guo et al. ${ }^{[9]}$ utilized nitrogenated carbon model catalysts based on highly-oriented pyrolytic graphite (HOPG) to demonstrate the correlation between ORR activity and the presence of pyridinic N-sites, while Favaro et al. used HOPG to explore the ORR activity with and without Pt-group metal nanoparticles. ${ }^{[23,24]}$ Recently, work from our group investigated the ORR at N-doped carbon using ultra-thin amorphous carbon electrodes as model systems to understand the activity as a function of $\mathrm{pH}$; our results demonstrated that the presence of predominantly pyridinic-N sites is a strong indicator for a high ORR onset potential at low $\mathrm{pH}$, whereas under alkaline conditions a high onset is more strongly correlated to the presence of graphitic-N sites and a highly graphitized carbon scaffold. ${ }^{[25]}$ 
Despite these advances, the specific roles of $\mathrm{N}_{\mathrm{G}}$ and $\mathrm{N}_{\mathrm{P}}$ sites in the ORR and any potential interplay between them through the carbon scaffold in which they are embedded are still not fully understood. In previous work from our group, we showed that the presence of $\mathrm{N}_{\mathrm{G}}$ sites in a highly graphitized carbon scaffold promotes the initial electron transfer to $\mathrm{O}_{2}$ in alkaline solutions, ${ }^{[25]}$ strongly influencing the observed onsets under these conditions. This was attributed to the bulk charge-transfer properties of the electrode rather than to interactions between $\mathrm{O}_{2}$ and specific chemical sites due to the outer-sphere nature of the first electron transfer step in the ORR at high $\mathrm{pH} .{ }^{[2],[27]}$ However, when assessing the overall activity of electrocatalysts, the selectivity of the ORR towards the full reduction of $\mathrm{O}_{2}$ to hydroxide is also important, in addition to achieving high onset potentials. The ORR is a multi-step process involving numerous chemisorbed intermediates, such as hydroperoxide radicals and anions $\left(\mathrm{HO}_{2} / \mathrm{HO}_{2}{ }^{-}\right)$, interacting with the surface. ${ }^{[4]}$ The overall ORR activity relies on the adsorption of these intermediates at specific chemical sites present in the carbon scaffold. The selectivity towards the complete $4 \mathrm{e}^{-}$reduction of $\mathrm{O}_{2}$ to hydroxide might therefore depend significantly on the ability of the catalytic electrode surface to rapidly progress through consecutive reduction steps, while out-competing side reactions, poisoning or desorption of intermediates. In this work we investigate the interplay between $\mathrm{N}_{\mathrm{G}}$ and $\mathrm{N}_{\mathrm{P}}$ sites and their effects on the overall activity of metal-free carbon electrodes in the ORR in alkaline solutions. To this end model systems with well-defined N-site composition, scaffold organization and smooth topography were prepared. A combination of X-Ray photoelectron spectroscopy (XPS), Raman spectroscopy, voltammetry, and density functional theory (DFT) calculations, were used to demonstrate that electrocatalytic performance of the $\mathrm{N}$-doped carbon is correlated to $\mathrm{N}$-site chemistry. We show that both $\mathrm{N}_{\mathrm{G}}$ and $\mathrm{N}_{\mathrm{P}}$ are responsible for high activity in metal-free carbon electrocatalysis; in particular, cooperative effects between these sites are essential to understand and effect selectivity in the ORR. These results suggest that careful engineering of $\mathrm{N}$-site 


\section{WILEY-VCH}

composition at graphitic carbons is essential to observe high activity at metal-free $\mathrm{N}$-doped carbon electrodes.

\section{Characterization of Model Nitrogen Doped Carbon Electrodes}

Model carbon electrodes for the study of activity in the ORR were prepared via a process of graphitization, starting from sputtered amorphous carbon thin-films as material precursors deposited on a geometrically well-defined glassy carbon disk insert (Figure 1a). The graphitization process preserves the smooth topography of the precursor thin-film (see Figure S1). This process enables model electrodes with different surface chemistry and composition to be compared to one another without the possible confounding factor of varying surface morphology and/or differences in porosity. Direct sputter deposition ensures low resistance electrical contacts and well-defined electrode geometry, without the need for binders (e.g. Nafion) or ink preparations, ${ }^{[28]}$ while the complete absence of metals or metal precursors in their synthetic route enables careful study of the intrinsic properties of carbon electrodes. Recent work from our group demonstrated that these electrode materials are ideal as model systems for investigating structure-activity relationships in electrocatalysis, ${ }^{[28,29]}$ including the ORR activity. ${ }^{[25]}$ While sputtered films have been used to study the ORR in the past, ${ }^{[17,30]}$ recent work from our group demonstrates that sputter-deposition followed by thermal annealing allows for the creation of carbon electrodes with a well-defined N-site chemistry and a controlled degree of structural disorder in the solid carbon scaffold. ${ }^{[29]}$

Two different methods were used, as illustrated schematically in Figure 1a. The first method (Figure 1a, top), was previously used to prepare model systems for ORR studies ${ }^{[25]}$ and involves the bulk nitrogenation of the carbon scaffold; this was achieved via the use of an $\mathrm{N}_{2} / \mathrm{Ar}$ plasma during the initial precursor film deposition, ${ }^{[28]}$ followed by post-deposition annealing at $900{ }^{\circ} \mathrm{C}$ under $\mathrm{N}_{2} .{ }^{[25,29]}$ This method resulted in nitrogenated amorphous carbon films referred to as aC:N 900. A second $\mathrm{N}$-doping method (Figure 1a, bottom) involved thermal treatment in $\mathrm{N}_{2} / \mathrm{NH}_{3}$ 


\section{WILEY-VCH}

atmosphere of a nitrogen-free carbon ( $\mathrm{a}-\mathrm{C}$ ) thin-film electrode; this protocol introduces nitrogen groups in the undoped carbon scaffold via surface reactions. Two different temperatures, $700{ }^{\circ} \mathrm{C}$ and $900{ }^{\circ} \mathrm{C}$ were employed and the materials are therefore denoted a-C $\mathrm{NH}_{3} 700$ and a-C $\mathrm{NH}_{3} 900$.

a)
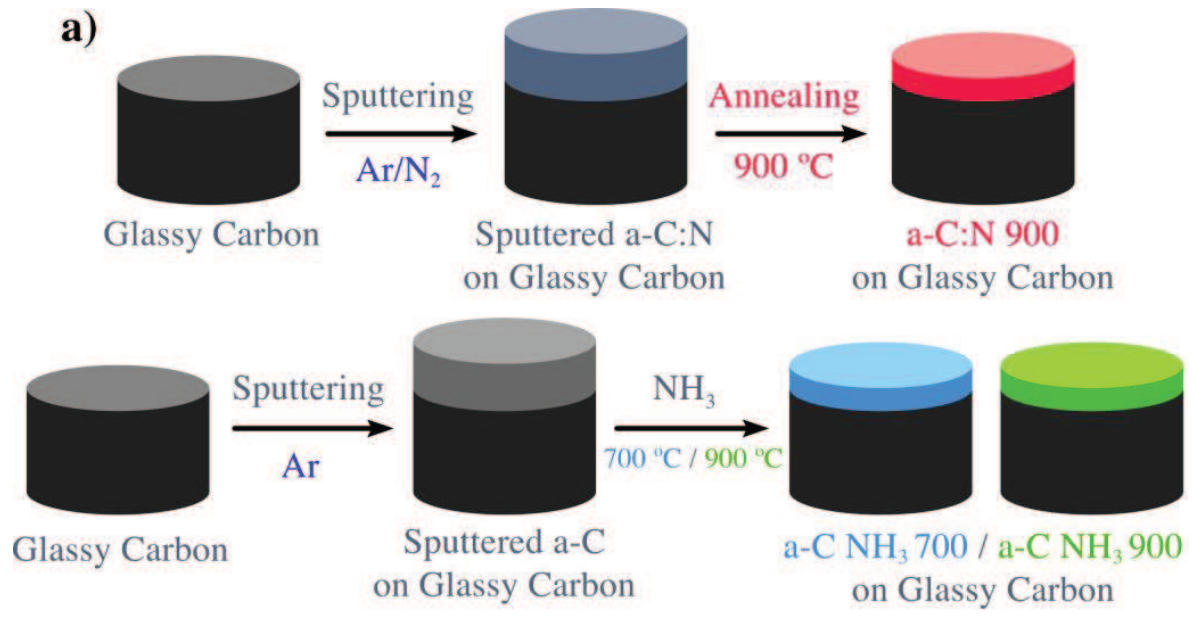

b)

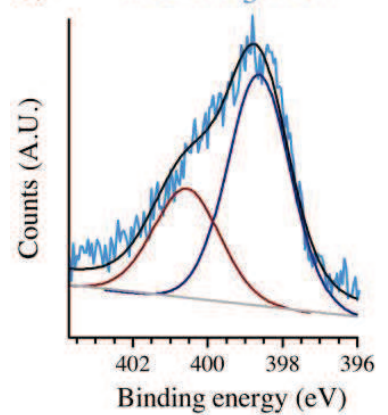

e)

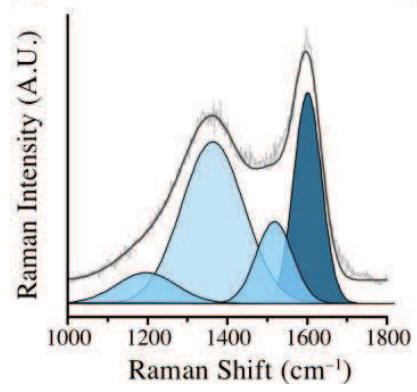

c)

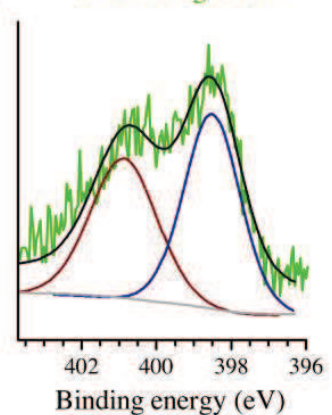

f)

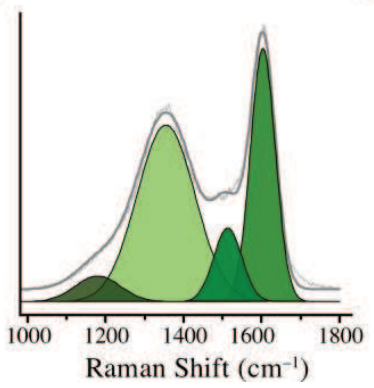

d)

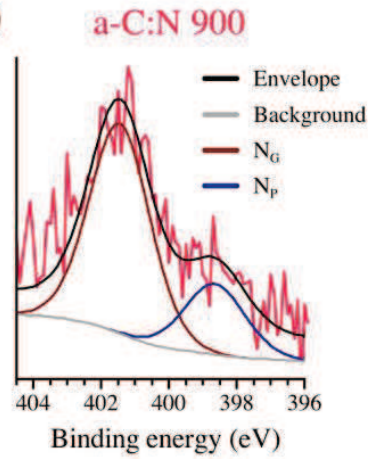

g)

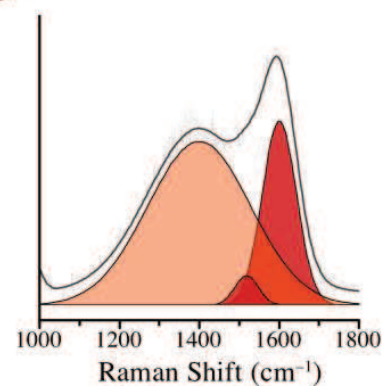

Figure 1. (a) Schematic illustrating the preparation of a-C:N 900 (Top) and a-C $\mathrm{NH}_{3}$ 700/900 (Bottom) surfaces. N 1s envelopes of b) a-C $\mathrm{NH}_{3} 700$ c) a-C $\mathrm{NH}_{3} 900$ and d) a-C:N 900 electrodes. The raw data and envelope are together offset from the components and background for clarity. Background-subtracted Raman spectra of e) a-C NH 3700 , f) a-C $\mathrm{NH}_{3} 900$ and g) a-C:N 900 electrodes. For clarity, in all cases the deconvoluted Raman spectra are plotted with the raw data and the envelope is offset from the component peaks. 
Table 1. O/C \%, N/C \% and N-site composition of a-C 900, a-C $\mathrm{NH}_{3} 700 / 900$ and a-C:N 900 materials obtained from XPS deconvolutions. Errors reported are 95\% confidence intervals $(n$ $=3$ in each case).

\begin{tabular}{|c|c|c|c|c|}
\hline Sample & $\mathrm{O} / \mathrm{C} \%$ & N/C \% & $\mathrm{N}_{\mathrm{P}} \%$ & $\mathrm{~N}_{\mathrm{G}} \%$ \\
\hline $\mathrm{a}-\mathrm{C} 900^{\mathrm{a})}$ & $3 \pm 2$ & - & - & - \\
\hline $\mathrm{a}-\mathrm{C} \mathrm{NH}_{3} 700$ & $2.4 \pm 0.7$ & $1.9 \pm 0.6$ & $64 \pm 9$ & $36 \pm 9$ \\
\hline a-C NH$H_{3} 900$ & $3 \pm 1$ & $1.9 \pm 0.5$ & $56 \pm 6$ & $43 \pm 6$ \\
\hline a-C:N $900^{\text {b) }}$ & $2.6 \pm 0.7$ & $2.4 \pm 0.6$ & $26 \pm 8$ & $74 \pm 8$ \\
\hline
\end{tabular}

${ }^{\text {a) Previously reported in Reference }}{ }^{[29]}$; b) Previously reported in Reference ${ }^{[25]}$

The deconvoluted XPS $\mathrm{N}$ 1s envelopes of both $\mathrm{NH}_{3}$-treated surfaces show two major contributions, as shown in Figure $1 \mathrm{~b}$ and 1c: a peak at $c a .398 \mathrm{eV}$, typically assigned to pyridinic $\mathrm{N}$ sites $\left(\mathrm{N}_{\mathrm{P}}\right)$, and a peak centered around $401 \mathrm{eV}$ assigned to graphitic $\mathrm{N}\left(\mathrm{N}_{\mathrm{G}}\right) \cdot{ }^{[2,31]}$ Figure $1 \mathrm{~d}$ shows the XPS in the $\mathrm{N} 1 \mathrm{~s}$ region and its deconvolution for a-C:N-900 electrodes; these samples possess predominantly $\mathrm{N}_{\mathrm{G}}$ sites with a minority contribution given by $\mathrm{N}_{\mathrm{P}}$ sites. This is consistent with previous work from our group ${ }^{[25,29]}$ and others ${ }^{[13,32]}$ on the evolution of nitrogenated carbon materials towards predominantly $\mathrm{N}_{\mathrm{G}} / \mathrm{N}_{\mathrm{P}}$ composition after thermal annealing. Finally, in order to serve as an undoped comparison material, a nitrogen-free electrode was also annealed at $900^{\circ} \mathrm{C}$ under inert $\mathrm{N}_{2}$ atmosphere to produce a graphitized electrode denoted a-C 900, with no N-sites as confirmed from both survey scans (Figure S2).

Table 1 summarizes results from XPS analysis for all of the electrodes examined. The O/C and $\mathrm{N} / \mathrm{C}$ at.\% contents were determined from the area ratios $\mathrm{A}_{\mathrm{O} 1 \mathrm{~s}} / \mathrm{A}_{\mathrm{Cls}}$ and $\mathrm{A}_{\mathrm{N} 1 \mathrm{~s}} / \mathrm{A}_{\mathrm{Cls}}$ respectively after correction by sensitivity factors. Based on the overlap of the $95 \%$ confidence intervals for both $\mathrm{O} / \mathrm{C}$ and $\mathrm{N} / \mathrm{C} \%$, these values are statistically indistinguishable for all of the nitrogenated electrodes studied. The relative proportions of $\mathrm{N}_{\mathrm{G}}$ and $\mathrm{N}_{\mathrm{P}}$ do differ between the three systems, with a-C:N 900 possessing predominantly $\mathrm{N}_{\mathrm{G}}$ sites and both a-C $\mathrm{NH}_{3}$ predominantly $\mathrm{N}_{P}$ sites. The a-C $\mathrm{NH}_{3} 900$ displays a small enhancement of $\mathrm{N}_{\mathrm{G}}$ sites at the expense of $\mathrm{N}_{\mathrm{P}}$ sites compared to the a-C $\mathrm{NH}_{3} 700$ (43 vs $36 \%$ ), which may possibly be attributed to the conversion of $\mathrm{N}_{\mathrm{P}}$ to 


\section{WILEY-VCH}

$\mathrm{N}_{\mathrm{G}}$ at the higher treatment temperature. ${ }^{[13]}$ Additionally, no elements other than $\mathrm{C}, \mathrm{N}$ and $\mathrm{O}$ are evident in the survey scans as discussed in the Supporting Information (Figure S2).

The effect of graphitization conditions on the organization of the carbon scaffold was probed via Raman spectroscopy. Figure 1e-g shows deconvoluted spectra of the three N-doped electrode materials, while the Raman spectrum and deconvolution of the nitrogen-free a-C 900 material is shown in the Supporting Information (Figure S4). All spectra show the characteristic features of disordered carbon materials, viz. the D peak at $c a .1350-1380 \mathrm{~cm}^{-1}$ and the G peak centered close to $1600 \mathrm{~cm}^{-1}{ }^{[33-35]}$ For both $\mathrm{NH}_{3}$-treated samples (Figure 1e and 1f) best fits were obtained using four Gaussian peaks, two to account for the D and G peaks, a third one centered close to $1510 \mathrm{~cm}^{-1}$ commonly referred to as the A peak, ${ }^{[29]}$ and finally a shoulder at $c a$. $1100 \mathrm{~cm}^{-1}$ known as the I peak. ${ }^{[36]}$ Both A and I peaks are characteristic of disordered carbons and may be attributed to the presence of both trigonally $\left(\mathrm{sp}^{2}\right.$-center) and tetrahedrally ( $\mathrm{sp}^{3}-$ center) bonded carbon atoms in amorphous regions that interconnect graphitic clusters in the solid. ${ }^{[36,37]}$ The deconvoluted Raman spectrum obtained for the a-C:N 900 surface (Figure 1g) was previously reported ${ }^{[25,29]}$ and consists of similar contributions from D, G and A peaks.

Relevant parameters obtained from Raman deconvolutions are summarized in Table 2. The G peak positions close to $1600 \mathrm{~cm}^{-1}$ and the relatively small values of full width at half maximum, G-FWHM $c a .100 \mathrm{~cm}^{-1}$ or less, indicate that these electrodes possess properties similar to those of nanocrystalline graphite ${ }^{[33]}$ Based on the three-stage model of Ferrari and Robertson, the intensity ratio $\mathrm{I}_{\mathrm{D}} / \mathrm{I}_{\mathrm{G}}$ gives a measure of disorder in the carbon scaffold and is inversely proportional to $L_{a}$, the average lateral dimension of the graphitic clusters. ${ }^{[38]}$ Undoped a-C 900 and $a-C \mathrm{NH}_{3} 700 / 900$ have similar $\mathrm{I}_{\mathrm{D}} / \mathrm{I}_{\mathrm{G}} \leq 0.75$, suggesting that these materials possess a similar degree of disorder and $L_{a}$ size. The smallest $\mathrm{I}_{\mathrm{D}} / \mathrm{I}_{\mathrm{G}}$ is observed for a-C $\mathrm{NH}_{3} 900$; this material also displays the narrowest G-FWHM thus indicating that it possesses the most extensive graphitized carbon network among those studied. The a-C:N 900 has the highest $\mathrm{I}_{\mathrm{D}} / \mathrm{I}_{\mathrm{G}}$ 


\section{WILEY-VCH}

$=0.84$ and G-FWHM, thus implying smaller cluster sizes and overall greater disorder. Based on these results the degree of order and graphitization in the scaffold increases as a-C:N $900<$ $\mathrm{a}-\mathrm{C} 900 \approx \mathrm{a}-\mathrm{C} \mathrm{NH} H_{3} 700<\mathrm{a}-\mathrm{C} \mathrm{NH} H_{3} 900$. This conclusion is further supported by photoemission measurements in the valence region which confirms an increase in metallic character among Ndoped materials in the order a-C:N $900 \approx \mathrm{a}-\mathrm{C} \mathrm{NH}_{3} 700<\mathrm{a}-\mathrm{C} \mathrm{NH}_{3} 900$ (see Figure S3).

Table 2. Raman Spectral Parameters of N-free and N-doped electrodes derived from the deconvolutions reported in Figure 2.

\begin{tabular}{|c|c|c|c|c|c|}
\hline Sample & $\mathrm{I}_{\mathrm{D}} / \mathrm{I}_{\mathrm{G}}$ & G position $/ \mathrm{cm}^{-1}$ & G FWHM / $\mathrm{cm}^{-1}$ & D position $/ \mathrm{cm}^{-1}$ & D FWHM $/ \mathrm{cm}^{-1}$ \\
\hline $\mathrm{a}-\mathrm{C} 900^{\mathrm{a})}$ & 0.74 & 1598 & 85 & 1379 & 274 \\
\hline $\mathrm{a}-\mathrm{C} \mathrm{NH}_{3} 700$ & 0.75 & 1599 & 78 & 1369 & 255 \\
\hline a-C NH 3900 & 0.72 & 1605 & 70 & 1355 & 186 \\
\hline $\mathrm{a}-\mathrm{C}: \mathrm{N} 900^{\mathrm{b})}$ & 0.84 & 1603 & 104 & 1385 & 279 \\
\hline
\end{tabular}

${ }^{\mathrm{a})}$ Previously reported in Reference ${ }^{[29]}$; b) Previously reported in Reference ${ }^{[25]}$

\section{Activity studies of nitrogen-doped electrodes towards the ORR}

The ORR activity of the three nitrogen-doped carbon materials was evaluated in $\mathrm{O}_{2}$-saturated $0.1 \mathrm{M} \mathrm{KOH}$ via linear sweep voltammetry (LSV) experiments using a rotating ring disk electrode (RRDE). Figure 2a shows the voltammograms obtained at $10 \mathrm{mV} \mathrm{s}^{-1}$ and $900 \mathrm{rpm}$ rotation at the disk after subtraction of capacitive current background; Table 3 summarizes key activity descriptors obtained from the RRDE experiments. The a-C $\mathrm{NH}_{3} 900$ electrode displays the highest ORR onset potential $\left(\mathrm{E}_{\mathrm{on}}\right)$, determined as the potential at which the current density reaches $0.1 \mathrm{~mA} \mathrm{~cm}^{-2}$, which at $0.83 \mathrm{~V}_{\text {RHE }}$ compares well with those of the most active metalfree N-doped carbons reported in literature. ${ }^{[2,14,18,21,39]}$ The bulk-doped a-C:N 900 electrode has the second highest onset potential $\mathrm{E}_{\mathrm{on}}=0.77 \mathrm{~V}_{\mathrm{RHE}}$, followed by a-C NH 3700 with $\mathrm{E}_{\mathrm{on}}=$ $0.73 \mathrm{~V}_{\text {RHE. }}$. The nitrogen-free carbon electrode shows poor activity (see Figure S5), as expected of an undoped carbon, with $\mathrm{E}_{\mathrm{on}}=0.65 \mathrm{~V}_{\mathrm{RHE}}$ comparable to that of undoped carbon electrodes as reported in previous studies. ${ }^{[25,40]}$ The a-C $\mathrm{NH}_{3} 900$ sample also displays the highest current 


\section{WILEY-VCH}

density in the region $<0.5 \mathrm{~V}_{\mathrm{RHE}}$ associated with mass-transport; the current density $|j|$ at 0.1 $\mathrm{V}_{\mathrm{RHE}}$ is close to the theoretical Levich current of $c a .4 .2 \mathrm{~mA} \mathrm{~cm}^{-2}$ for a $4 \mathrm{e}$-reduction of $\mathrm{O}_{2}$ at $900 \mathrm{rpm}^{[41,42]} \mathrm{a}-\mathrm{C} \mathrm{NH}_{3} 700$ and a-C:N 900 electrodes display significantly lower values of $|j|$ at the same potential, suggesting that these surfaces do not promote the complete 4e-reduction of oxygen to hydroxide.
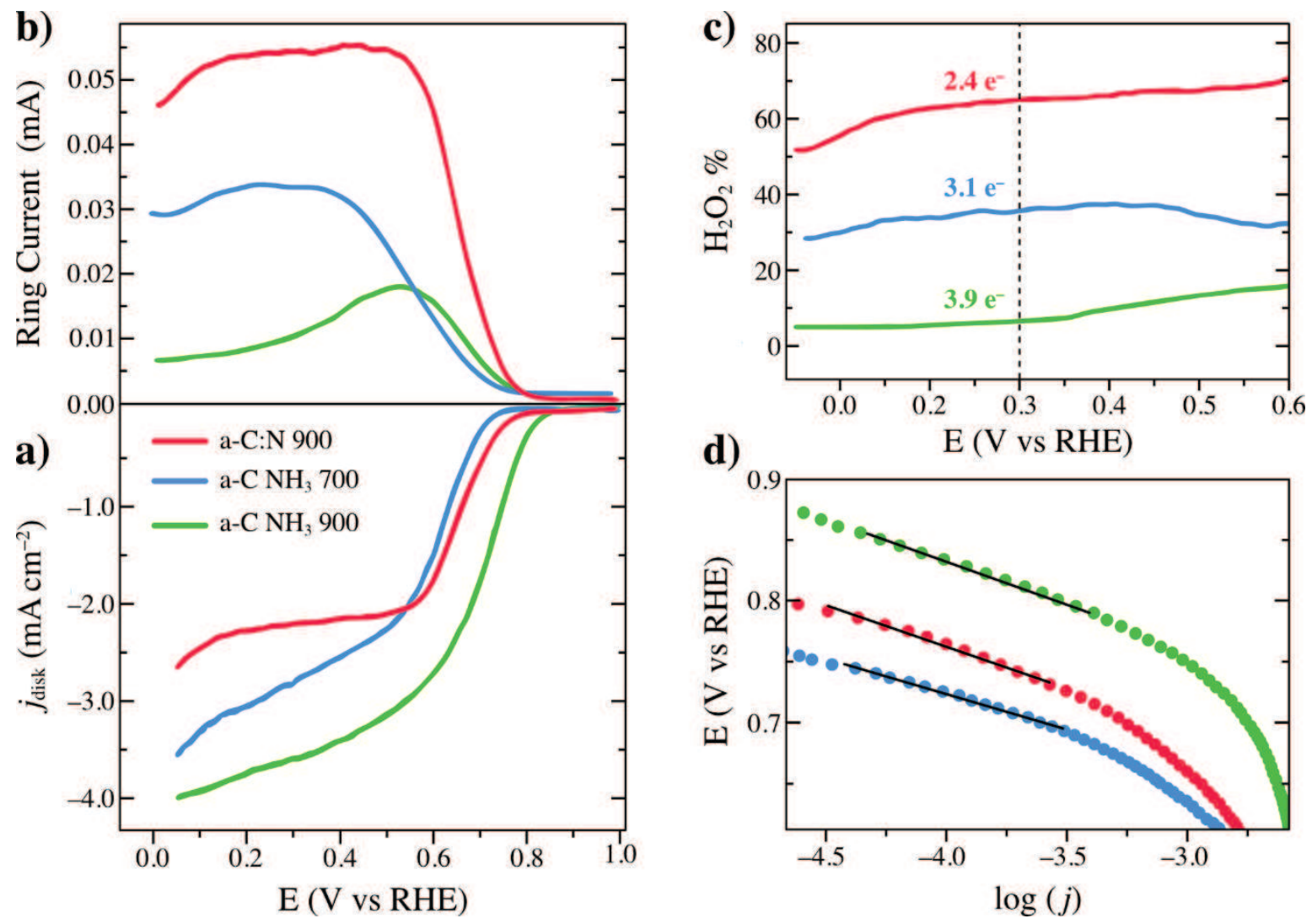

Figure 2. (a) Linear sweep voltammograms and (b) corresponding ring currents of nitrogenated carbon electrodes obtained in $\mathrm{O}_{2}$-saturated $0.1 \mathrm{M} \mathrm{KOH}$ at $10 \mathrm{mV} \mathrm{s}^{-1}$ and a rotation rate of 900 rpm using a rotating ring disk electrode (RRDE). All curves are shown after subtraction of the capacitive current background obtained in $\mathrm{N}_{2}$-saturated electrolyte. $E_{\text {on }}$ at $0.1 \mathrm{~mA} \mathrm{~cm}^{-2}$ were found to be $0.83 \mathrm{~V}_{\mathrm{RHE}}\left(\mathrm{a}-\mathrm{C} \mathrm{NH} \mathrm{NH}_{3} 900\right), 0.77 \mathrm{~V}_{\mathrm{RHE}}$ (a-C:N 900) and $0.73 \mathrm{~V}_{\mathrm{RHE}}\left(\mathrm{a}-\mathrm{C} \mathrm{NH}_{3} 700\right.$ ). (c) \% Yields of peroxide detected at the ring from the reduction process; the average number of electrons transferred at $0.3 \mathrm{~V}_{\mathrm{RHE}}$ is displayed above the corresponding trace in each case. (d) Tafel plots of the three nitrogenated carbon electrodes.

Figure 2b shows the corresponding ring current $\left(I_{R}\right)$ data, which reveals further significant differences in activity among the three electrodes. The onset of the ring current coincides with the onset of the disk current in each case, thus confirming that the ring current originates from 


\section{WILEY-VCH}

peroxide production at the disk. Figure $2 \mathbf{c}$ shows the $\mathrm{H}_{2} \mathrm{O}_{2} \%$ yield calculated from $\mathrm{I}_{R}$ data as described in the experimental section; note that the detected species is actually the hydroperoxide anion as the $\mathrm{pK}_{\mathrm{a}}$ of $\mathrm{H}_{2} \mathrm{O}_{2}$ is $11.63 .{ }^{[26]}$ The dashed line in Figure $2 \mathbf{c}$ indicates the potential at which the yield of $\mathrm{H}_{2} \mathrm{O}_{2}$ and the number of electrons $(n)$ are reported in Table 3. The a-C:N 900 and a-C NH 3700 electrodes show an increase in $\mathrm{I}_{\mathrm{R}}$ after the onset of ORR followed by a plateau at potentials lower than $0.5 \mathrm{~V}_{\mathrm{RHE}}$. The peroxide yield is highest at the a-C:N 900 electrode, consistent with this electrode displaying the lowest values of limiting current density $\left(c a .2 \mathrm{~mA} \mathrm{~cm}^{-2}\right)$ and the lowest value of $n=2.4$, which indicates a predominantly 2e-reduction pathway for $\mathrm{O}_{2}$. The a-C $\mathrm{NH}_{3} 900$ material displays a remarkably different current profile at the ring with a clearly identifiable peak, reaching a maximum in $I_{R}$ around $0.5 V_{R H E}$ followed by a decrease at higher overpotentials. This peak corresponds to an initial presence of 2e-reduction close to the ORR onset potential which decreases in importance as the overpotential is increased and the full 4e-reduction becomes the predominant pathway. ${ }^{[26]}$ At $0.3 \mathrm{~V}_{\text {RHE }}$ the $\mathrm{H}_{2} \mathrm{O}_{2} \%$ is as low as $6 \%$, which is consistent with an almost complete 4e-reduction of $\mathrm{O}_{2}(n=3.9)$.

Tafel plots are shown in Figure 2d; all Tafel slopes were found to be between $60-80 \mathrm{mV} \mathrm{dec}{ }^{-1}$, which is consistent with a microkinetic model in which the rate determining step (rds) of the ORR is a chemical step occurring after a non rate-determining electron transfer step. ${ }^{[43]} \mathrm{We}$ note that Tafel slopes of $c a .60 \mathrm{mV} \mathrm{dec}{ }^{-1}$ have previously been observed for the ORR on Pt electrodes and attributed to the first electron transfer being the rds, despite a value of 120 $\mathrm{mV} \operatorname{dec}^{-1}$ being expected for such an rds. ${ }^{[44]}$ This discrepancy is typically ascribed to the presence of an adsorbate layer on Pt; however, in the case of these carbon electrodes interference from adsorbate layers can be excluded based on the overlapping cathodic and anodic sweeps in the CV, as shown in the Supporting Information (Figure S6). 
Table 3. Summary of ORR activity descriptors obtained from RRDE experiments using aC 900, a-C NH $33700 / 900$ and a-C:N 900 electrodes. All voltages are referenced relative to RHE.

\begin{tabular}{ccccc}
\hline Sample & $\begin{array}{c}\mathrm{E}_{\mathrm{ON}} \\
\mathrm{V} @ 0.1 \\
\mathrm{~mA} \mathrm{~cm}\end{array}$ & $\begin{array}{c}\mathrm{n} \\
@ 0.3 \mathrm{~V}\end{array}$ & $\mathrm{H}_{2} \mathrm{O}_{2} \% @ 0.3 \mathrm{~V}$ & $\begin{array}{c}|j| \\
\left(\mathrm{mA} \mathrm{cm} \mathrm{cm}^{-2}\right) \\
(0.1 \mathrm{~V}\end{array}$ \\
\hline a-C-900 & 0.65 & 2.6 & 70 & 2.3 \\
a-C- $\mathrm{NH}_{3}-700$ & 0.73 & 3.1 & 35 & 3.4 \\
a-C-NH-900 & 0.83 & 3.9 & 6 & 3.9 \\
a-C:N-900 & 0.77 & 2.4 & 65 & 2.4 \\
\hline
\end{tabular}

\section{ORR Selectivity and Cooperative Effects}

The complete 4e-reduction of $\mathrm{O}_{2}$ to hydroxide anion (Eq. 1) is the most desirable outcome of the ORR for fuel cell applications, however partial 2e-reduction leading to the formation of hydroperoxide anion $\left(\mathrm{HO}_{2}{ }^{-}\right)$(Eq. 2) is also possible. If the $\mathrm{HO}_{2}{ }^{-}$intermediate is desorbed from the electrode into solution it can be detected via RRDE methods; however, if $\mathrm{HO}_{2}{ }^{-}$is formed at the electrode surface and remains adsorbed it can be reduced by a further $2 \mathrm{e}$ to hydroxide (Eq. 3).

$$
\begin{array}{ll}
\mathrm{O}_{2}+2 \mathrm{H}_{2} \mathrm{O}+4 \mathrm{e}^{-} \rightarrow 4 \mathrm{OH}^{-} & \mathrm{E}^{\circ}=1.229 \mathrm{~V} \text { vs. RHE } \\
\mathrm{O}_{2}+\mathrm{H}_{2} \mathrm{O}+2 \mathrm{e}^{-} \rightarrow \mathrm{HO}_{2}^{-}+\mathrm{OH}^{-} & \mathrm{E}^{\circ}=0.695 \mathrm{~V} \text { vs. RHE }{ }^{[45]} \\
\mathrm{HO}_{2}^{-}+\mathrm{H}_{2} \mathrm{O}+2 \mathrm{e}^{-} \rightarrow 30 \mathrm{H}^{-} & \mathrm{E}^{\circ}=1.763 \mathrm{~V} \text { vs. RHE }
\end{array}
$$

The most striking difference among the three materials examined emerges from analysis of the ring currents arising from $\mathrm{HO}_{2}{ }^{-}$detection, particularly at potentials $<0.5 \mathrm{~V}$ RHE (Figure $2 b$ ). Detection of $\mathrm{HO}_{2}{ }^{-}$constitutes evidence of a series pathway in which hydroperoxide is detectable because desorption of intermediate species competes effectively with the complete reduction to hydroxide. ${ }^{[46]}$ However, results on the three N-doped carbon materials investigated demonstrate that even for materials with similar N/C and $\mathrm{O} / \mathrm{C}$ composition, subtle differences in the chemical properties of N-sites result in dramatic changes in peroxide yields. While 
a-C:N 900 and a-C $\mathrm{NH}_{3} 700$ suggest a predominance of the 2e-pathway, the a-C $\mathrm{NH}_{3} 900$ surface yields almost exclusively the 4e-reduction.

To understand how the chemistry of metal-free $\mathrm{N}$-doped carbons can be tailored to increase selectivity towards a complete 4e-reduction it is necessary to examine in greater detail the mechanistic steps involved in the reduction process. On Pt and other precious-metal ORR catalysts it is widely accepted that adsorption of $\mathrm{O}_{2}$ is the first step in the ORR mechanism, while the first electron transfer is the rds. ${ }^{[27]}$ This inner sphere electron transfer (ISET) mechanism may be followed at low and high $\mathrm{pH}$; however, in alkaline media, an outer-sphere electron transfer (OSET) becomes also possible (Eq. 4), as highlighted by Markovic et al. on Ag electrodes ${ }^{[26]}$ and more generally by Ramaswamy and Mukerjee..$^{[27,47]}$

$\mathrm{O}_{2(\mathrm{aq})}+\mathrm{e}^{-} \rightarrow \mathrm{O}_{2}^{--}{ }_{(\mathrm{aq})} \quad \mathrm{E}^{\circ}=-0.33 \mathrm{~V}$ vs $\mathrm{SHE}^{[48]}$

We have recently investigated the alkaline ORR on metal-free a-C:N electrodes and demonstrated that trends in onset potential are best explained by a mechanism with an initial OSET to solvated oxygen in alkaline solutions such as that in Eq. ${ }^{\left[{ }^{[25]}\right.}$ Reaction 4 is $\mathrm{pH}$ independent and its standard potential is only $0.44 \mathrm{~V}$ vs. RHE at $\mathrm{pH} 13$. As discussed by Blizanac et al., ${ }^{[26]}$ as the $\mathrm{pH}$ increases the potential of the 4e-reduction (Eq. 1) approaches that of Eq. 4 and a difference between them of $c a .1 .5 \mathrm{~V}$ under standard conditions can be reduced to less than $0.8 \mathrm{~V}$ at $\mathrm{pH} 13$. This enables ORR catalysis at high $\mathrm{pH}$ by a range of non-precious materials, including carbon, since weaker non-covalent interactions such as H-bonding to the superoxide anion may be sufficient to overcome the potential difference to the first electron transfer. ${ }^{[25,27,49]}$

Based on Tafel analysis, reaction 4, however, cannot constitute the rds of the overall ORR; the Tafel slopes of all three $\mathrm{N}$-doped surfaces are consistent instead with the rds being a chemical step preceded by a fast electron transfer. ${ }^{[43]}$ This suggests that chemical rearrangements that take place after the formation of the superoxide anion determine the overall rate of the ORR, 
while the position of the rds in the reaction mechanism can be expected to affect the $4 \mathrm{e} / 2 \mathrm{e}$ selectivity of the reaction. Hence, it is important to examine how the structure and composition of $\mathrm{N}$-sites might affect the outcome of reactions that follow the first electron transfer to $\mathrm{O}_{2}$ as this can provide insights into the properties of the $\mathrm{N}$-doped carbon surface that determine selectivity.

Upon generation of the superoxide anion, this species may be adsorbed (Eq. 5) and protonated (Eq. 6) to yield a hydroperoxyl radical $\left(\mathrm{HO}_{2}{ }^{\circ}\right) \cdot{ }^{[27,50]}$ Further reduction of $\left(\mathrm{HO}_{2}{ }^{\circ}\right)$ ads is possible as in Eq. 7 or, alternatively, by superoxide as in Eq. 8:

$$
\begin{aligned}
& \mathrm{O}_{2(\mathrm{aq})}^{\cdot-} \rightarrow\left(\mathrm{O}_{2}^{\cdot-}\right)_{\text {ads }} \\
& \left(\mathrm{O}_{2}^{\cdot-}\right)_{a d s}+\mathrm{H}_{2} \mathrm{O} \rightarrow\left(\mathrm{HO}_{2}^{\cdot}\right)_{a d s}+\mathrm{OH}^{-} \\
& \left(\mathrm{HO}_{2}^{-}\right)_{a d s}+\mathrm{e}^{-} \rightarrow \mathrm{HO}_{2}^{-} \\
& \left(\mathrm{HO}_{2}^{-}\right)_{a d s}+\mathrm{O}_{2(\mathrm{aq})}^{--} \rightarrow \mathrm{HO}_{2}^{-}+\mathrm{O}_{2}
\end{aligned}
$$

If superoxide is not adsorbed, it may instead react with water through a well-established homogeneous pathway: ${ }^{[51]}$

$2 \mathrm{O}_{2}^{--}+\mathrm{H}_{2} \mathrm{O} \rightarrow \mathrm{HO}_{2}^{-}+\mathrm{O}_{2}+\mathrm{OH}^{-}$

The $\mathrm{HO}_{2}{ }^{-}$detected in RRDE studies may therefore be produced via the disproportionation of superoxide (Eq. 9), via reduction of $\mathrm{HO}_{2}{ }^{\bullet}$ (Eq. 7) or via reaction of adsorbed $\mathrm{HO}_{2}{ }^{\bullet}$ with superoxide (Eq. 8). Conversely, an absence of a $\mathrm{HO}_{2}{ }^{-}$current at the ring can be observed only if intermediates $\mathrm{O}_{2}^{-}, \mathrm{HO}_{2}{ }^{\bullet}$ and $\mathrm{HO}_{2}^{-}$remain adsorbed at the surface. The importance of the binding energy of reaction intermediates has been acknowledged for the selectivity of the ORR at $\mathrm{Pt}$ in alkaline solutions. For instance, Ramaswami et al. ${ }^{[27]}$ proposed that weak interactions between $\mathrm{HO}_{2}{ }^{-}$and the Pt-Oxide substructure result in lower 4e-selectivity. Mayrhofer et al. ${ }^{[46]}$ have also argued that it is the competition between the desorption of the peroxide intermediates from the electrode surface and the second 2e-transfer in the ORR pathway, which ultimately 


\section{WILEY-VCH}

determines the overall activity. If the kinetics of hydrogen peroxide reduction are sluggish and/or desorption of peroxide from the surface is facile, the end product of $\mathrm{O}_{2}$ reduction is likely to be hydrogen peroxide or its anion. ${ }^{[46]}$ Species that interfere with the adsorption of intermediates, including adsorbed spectator ions or the poisoning of reactive sites, are therefore expected to result in increased production of hydroperoxide and a degradation of the ORR activity.

To shed light on the different ORR behaviors observed for the three N-doped carbon materials (Figure 2), we carried out a thorough mechanistic investigation by means of density functional theory (DFT) methods detailed in the Experimental Section. With this theoretical analysis, we aimed at untangling the effect of the composition of $\mathrm{N}$-sites on the ORR activity and selectivity, as well as potential cooperative effects that might arise from the coexistence of $\mathrm{N}_{\mathrm{G}}$ and $\mathrm{N}_{\mathrm{P}}$ sites in the same carbon scaffold. The ORR mechanism and the model graphene clusters considered in the calculations are shown in Figure 3. The model clusters were chosen to display the same nitrogen content but different $\mathrm{N}$-site composition: two clusters were designed with $\mathrm{N}_{\mathrm{G}}\left(2 \mathrm{~N}_{\mathrm{G}^{-}}\right.$ Gr) and $\mathrm{N}_{\mathrm{P}}\left(2 \mathrm{~N}_{\mathrm{P}-\mathrm{Gr}}\right)$ sites, exclusively, while a third graphene cluster was designed with an equal $\mathrm{N}_{\mathrm{G}}$ and $\mathrm{N}_{\mathrm{P}}$ site $\left(\mathrm{N}_{\mathrm{G}} \mathrm{N}_{\mathrm{P}}-\mathrm{Gr}\right)$ composition. These models therefore resemble the main differences in composition among the three electrodes a-C:N 900 (predominantly $\mathrm{N}_{\mathrm{G}}$ ), a-C NH 700 (predominantly $\mathrm{N}_{\mathrm{P}}$ ), and a-C $\mathrm{NH}_{3} 900\left(\mathrm{~N}_{\mathrm{G}} / \mathrm{N}_{\mathrm{P}}\right.$ in similar concentrations). Initial calculations revealed that the three $\mathrm{N}$-doped carbon electrodes are thermodynamically more stable in their oxidized form over the potential window of interest (Table S1-S3), which led us to consider these as the starting point for subsequent reactivity studies. After assessing the resting state of these systems, the Gibbs energies of the relevant ORR intermediates in the mechanism shown in Figure 3a (i.e. $\mathrm{HO}_{2} \bullet, \mathrm{HO}_{2}{ }^{-}$and $\mathrm{HO} \bullet$ ) were computed considering a total of 52 different active sites; of these, 12 were excluded as active sites of interest on the basis of a lack of stable adsorption of any one of the three ORR intermediates considered in Figure 3a (see Figure S8 


\section{WILEY-VCH}

for details). The $\Delta \mathrm{G}$ values obtained at each of these sites were subsequently used to calculate the corresponding theoretical ORR potential, defined as the voltage at which the $4 \mathrm{e}^{-}$reduction becomes thermodynamically favorable.

a)

Step 1: $\mathrm{O}_{2}+\mathrm{H}_{2} \mathrm{O}+\mathrm{e}^{-} \rightarrow \mathrm{HOO}^{*}+\mathrm{OH}^{-}$

Step 2: $\mathrm{HOO}^{*}+\mathrm{e}^{-} \rightarrow \mathrm{HOO}^{-}$

Step 3: $\mathrm{HOO}^{*-}+\mathrm{H}_{2} \mathrm{O}+\mathrm{e}^{-} \rightarrow \mathrm{HO}^{*}+2 \mathrm{OH}^{-}$

Step 4: $\mathrm{HO}^{*}+\mathrm{e}^{-} \rightarrow \mathrm{OH}^{-}$

c)

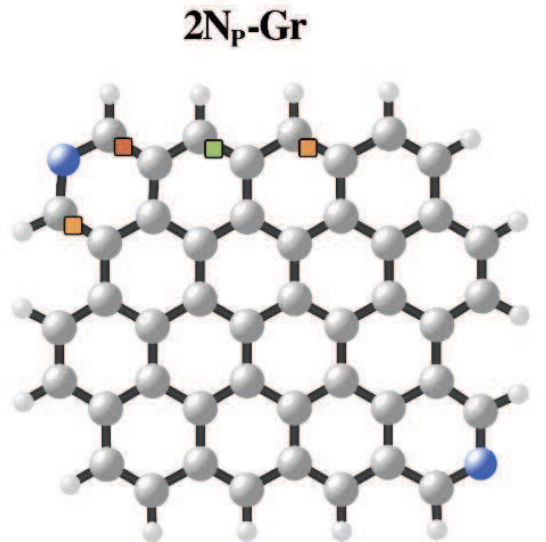

b)

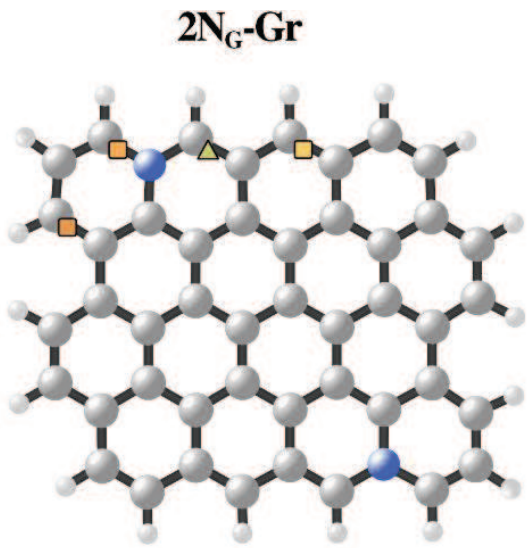

d)

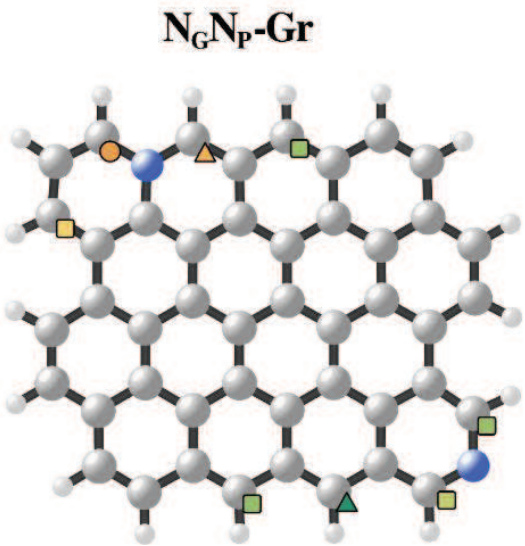

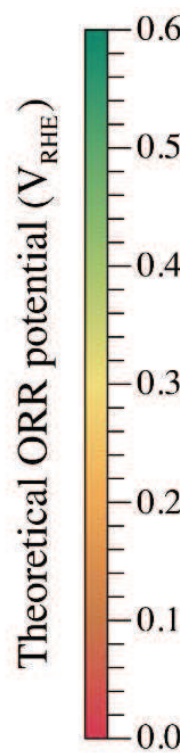

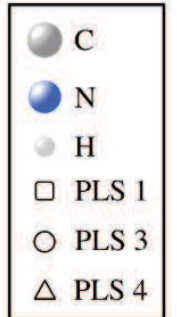

Figure 3. a) Investigated ORR reaction mechanism. b-d) Model structures of the N-doped carbon surfaces employed in DFT calculations. The potential limiting step (PLS) and theoretical ORR potential for the best active sites are indicated with full squares (Step 1), circles (Step 3) and triangles (Step 4) using the color-code bar on the right-hand side of b). All the active sites and their corresponding theoretical potentials are reported in Table S4-S6.

Figures 3b-d show the most active sites on the three surfaces, which correspond to $\mathrm{C}$ atoms located one to five bonds away from the $\mathrm{N}_{\mathrm{G}}$ and $\mathrm{N}_{\mathrm{P}}$ sites. Interestingly, despite the proximity of these sites, the computed theoretical ORR potentials are found to span between 0.0 and 0.6 $\mathrm{V}_{\mathrm{RHE}}$, indicating that ORR activity is very sensitive to both the $\mathrm{N}$-sites present in the carbon scaffold and the local environment around the active site. Based on the best (highest) predicted 


\section{WILEY-VCH}

theoretical ORR potentials for each model cluster, the performance towards the $4 \mathrm{e}^{-}$reduction is ranked in the order $\mathrm{N}_{\mathrm{G}} \mathrm{NP}_{\mathrm{P}} \mathrm{Gr}>2 \mathrm{~N}_{\mathrm{P}}-\mathrm{Gr} \simeq 2 \mathrm{~N}_{\mathrm{G}}-\mathrm{Gr}$, which agrees well with the preference for the $4 \mathrm{e}^{-}$pathway observed in experiments.

The calculated ORR potentials, and the reaction steps that define them, i.e. the potential limiting steps (PLS), also provide insights on the experimental trend observed for the onset potentials and the peroxide yield at the ring electrode. Figures 3b-d summarize the PLS identified for each of the best ORR active sites predicted by computational studies. According to our simulations, the active site with the highest theoretical potential for $\mathrm{N}_{\mathrm{G}} \mathrm{Np}_{\mathrm{P}} \mathrm{Gr}$ and $2 \mathrm{~N}_{\mathrm{G}}-\mathrm{Gr}$ displays step 4 as the PLS, which involves the reduction of $\mathrm{HO}^{\bullet}$ to $\mathrm{OH}^{-}$. In contrast, for $2 \mathrm{NP}-\mathrm{Gr}$ the PLS corresponds to step 1, that is the initial reduction from $\mathrm{O}_{2}$ to $\mathrm{HOO} \cdot$. Figure 4 shows the calculated Gibbs energy diagrams for the ORR at the most active site for the three different model surfaces at an applied potential of $1.23 \mathrm{~V}_{\text {RHE}}$. The PLS determines in each case the corresponding theoretical ORR potential, i.e. $0.56\left(\mathrm{~N}_{\mathrm{G}} \mathrm{N}_{\mathrm{P}}-\mathrm{Gr}\right), 0.41\left(2 \mathrm{~N}_{\mathrm{P}-\mathrm{Gr}}\right)$ and $0.36\left(2 \mathrm{~N}_{\mathrm{G}}-\right.$ Gr) $V_{\text {RHE, }}$ which agree with the experimental trend and explains the good ORR onsets observed with these electrodes. The equivalent diagram in Figure 4 was also calculated at a voltage of $0.36 \mathrm{~V}_{\mathrm{RHE}}$, the potential at which all reaction steps for the three clusters become thermodynamically favorable and is shown in Figure S9. Interestingly, the computational findings show that step 1 becomes less energy demanding after the introduction of $\mathrm{N}_{\mathrm{G}}$ sites in the cluster, thus shifting the PLS to a later stage in the $\mathrm{O}_{2}$ reduction sequence, as previously mentioned. Given that the relative Gibbs energy $(\Delta \mathrm{G})$ of step 1 includes the energy change associated with the first OSET, protonation and adsorption of $\mathrm{HOO} \cdot$, this suggests that an increase in $\mathrm{N}_{\mathrm{G}-\mathrm{S}}$ ites might be desirable to lower the $\Delta \mathrm{G}$ cost of the initial steps in the ORR sequence, in general agreement with experimental observations in alkaline solutions reported in a recent work, that showed that $\mathrm{N}_{\mathrm{G}}$-enrichment correlates with improvements in the onset of the disk currents. ${ }^{[25]}$ 


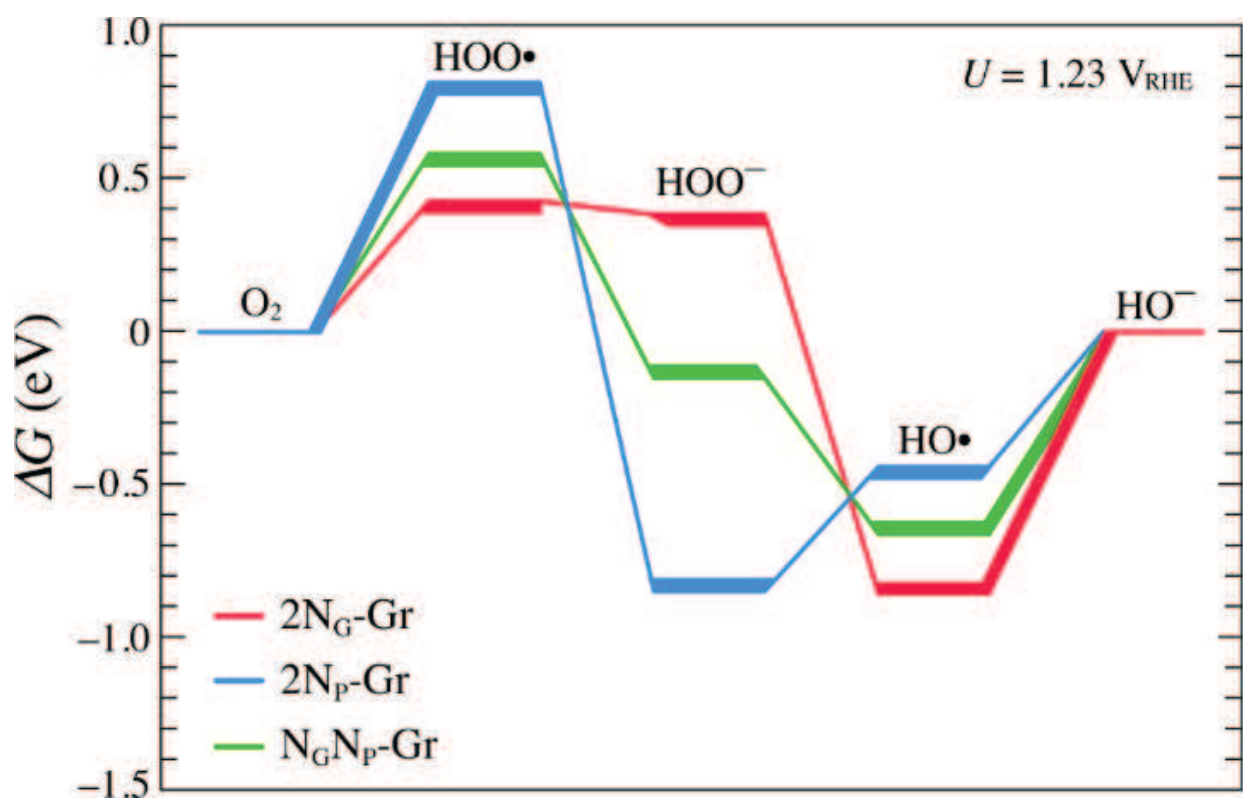

Figure 4. Calculated Gibbs energy diagram at $1.23 \mathrm{~V}_{\mathrm{RHE}}$ for the ORR at the most active sites on each the modelled N-doped carbon surface. The thicker lines are used to indicate the PLS for each cluster.

Remarkable differences in the adsorption energies of critical ORR intermediates depending on $\mathrm{N}$-site composition of the clusters emerge from the results in Figure 4. DFT calculations predict the weakest binding for the $\mathrm{HO}_{2}{ }^{-}$intermediate for the homogeneous $2 \mathrm{~N}_{\mathrm{G}}-\mathrm{Gr}$ cluster. This suggests that, on these $\mathrm{N}_{\mathrm{G}}$-rich surfaces, $\mathrm{HO}_{2}{ }^{-}$desorption competes more effectively with its subsequent reduction to $\mathrm{HO}^{-}$compared to the other two clusters. On the other hand, the homogeneous $2 \mathrm{~N}_{\mathrm{P}}$-Gr cluster displays the weakest adsorption energy for the hydroperoxyl

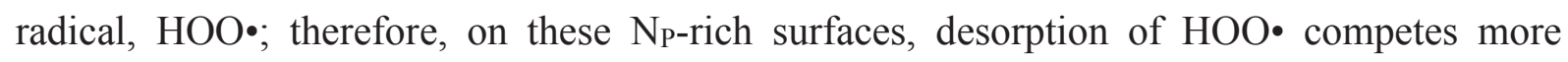
effectively with subsequent reductions than in the case of the other two clusters. Both $\mathrm{HO}_{2}{ }^{-}$ and $\mathrm{HOO} \bullet$ desorption are expected to result in higher hydroperoxide oxidation currents at the ring electrode, in the former case via direct detection of the desorbed intermediate, while in the latter via homogeneous reductions by superoxide or its protonated form. Interestingly, calculations predict that the coexistence of $\mathrm{N}_{\mathrm{G}}$ and $\mathrm{N}_{\mathrm{P}}$ sites in similar proportions is an important requirement to achieve the right distribution of the energy levels for these two ORR 


\section{WILEY-VCH}

intermediates: adsorption energies are neither too weak that they could favor desorption, nor too strong that they could make further reduction more endergonic.

These findings are in striking agreement with experimental data on the three electrodes studied. The electrode materials with predominantly $\mathrm{N}_{\mathrm{G}}$ or $\mathrm{N}_{\mathrm{p}}$-sites, i.e. a-C:N 900 and a-C NH3 700, yield significant ring currents and lower number of electrons. The computational results suggest that this might be explained by poor stability of the hydroperoxyl and hydroperoxide adsorbate intermediates, respectively; the weakly bound species is different in each of these two extreme cases, however desorption of both of them would result in enhanced hydroperoxide production during ORR. The electrode materials that possess approximately similar concentrations of $\mathrm{N}_{\mathrm{G}}$ and $\mathrm{N}_{\mathrm{P}}$-sites result in the lowest hydroperoxide production thus suggesting that simultaneous presence of both $\mathrm{N}$-sites can regulate the binding strength of intermediates and facilitate the progression of the 4e-reduction to the final hydroxide species.

\section{Conclusions}

In this paper the ORR performance of metal-free $\mathrm{N}$-doped carbon model systems with constant $\mathrm{N} / \mathrm{C}$ content but varying composition of graphitic-N and pyridinic-N sites was investigated under alkaline conditions. Experimental and computational studies confirm that the presence of both pyridinic-N and graphitic-N are important for facilitating the 4e-reduction. Electrode materials with predominantly pyridinic-N or graphitic-N were found to display poorer onset potentials and selectivity, whereas materials with similar proportion of these two sites were found to be the best performers, displaying a high onset potential and almost negligible hydroperoxide yields. For all materials tested, a Tafel analysis suggests that chemical rearrangements of intermediate species might constitute the limiting step in the reduction process. This prompted a computational study of the reduction mechanism with a focus on understanding the stabilization of the hydroperoxyl radical and hydroperoxide intermediates. 


\section{WILEY-VCH}

First, computational results confirmed the importance of $\mathrm{N}_{\mathrm{G}}$-sites in reducing the $\Delta \mathrm{G}$ associated with the formation of hydroperoxyl radical intermediates. Second, they suggest that homogeneous $\mathrm{N}$-site compositions result in weakly bound intermediates when compared to carbon scaffolds that possess balanced graphitic/pyridinic N-site composition. Both of these sites are synergistically involved in regulating the adsorption stabilization of intermediates which in turn facilitates the progression of the reduction to the final hydroxide product. An important conclusion to be drawn from our results is that the presence of a specific site does not in itself guarantee high ORR activity. Since on these metal-free materials the ORR proceeds via an OSET, the 'non-local' effect of $\mathrm{N}_{\mathrm{G}}$ sites as carbon dopants is expected to remain an important factor in terms of facilitating the first electron transfer. Therefore, the metallic character and the degree of graphitization of the doped carbon scaffold are likely to remain important for enhancing activity. However, following generation of superoxide via Eq. 4, our computational findings indicate that binding of intermediates, particularly $\mathrm{HO}_{2}{ }^{-}$is crucial for obtaining a full 4e-reduction, as previously proposed for ORR at Pt electrodes. This 'local' effect of N-doping within the carbon cluster is an important predictor of selectivity, a key marker of high performing ORR electrocatalysts. Given that significant changes in theoretical potentials and selectivity were observed computationally for clusters in which the $\mathrm{N}_{\mathrm{G}}-\mathrm{N}_{\mathrm{P}}$ distance is greater than $5 \mathrm{C}-\mathrm{C}$ bonds it would be interesting to elucidate whether their relative positioning can be regulated, for instance by engineering the lateral dimension of graphitic clusters, to further enhance activity and selectivity; studies are currently underway to investigate the length scales relevant to these cooperative effects.

These findings offer important insights on guiding principles for the synthesis of high performing metal-free N-doped carbons. Bottom up approaches using carbon building blocks with controlled relative positioning of graphitic/pyridinic sites, such as graphene quantum dots or nano-graphene precursors of nanoribbons, could offer a synthetic route to smart metal-free 


\section{WILEY-VCH}

carbon electrocatalysts. Similarly, top down approaches involving carbon doping followed by scaffold nanoengineering to control graphitization and average distance between graphitic and pyridinic sites might also be a scalable approach for the synthesis of selective $\mathrm{N}$-doped materials for the ORR.

\section{Experimental Section}

Chemicals and Materials: $\mathrm{KOH}$ was purchased from Sigma Aldrich semiconductor grade pellets, 99.99\%). Electrodes were prepared using glassy carbon (GC) disks (Ø 5mm HTW, Germany) as substrates. The disks were first polished using alumina slurries as previously reported ${ }^{[25,29]}$ For XPS and Raman measurements B-doped silicon wafers (MicroChemicals; resistivity $5-10 \Omega \mathrm{cm}$ ) were used as substrates. ${ }^{[28]}$

Preparation of N-Doped Carbon Model Systems: a-C:N 900 electrodes were prepared by DC magnetron sputtering followed by thermal annealing under $\mathrm{N}_{2}$ as previously reported. ${ }^{[25,}{ }^{29]}$ Briefly, the a-C:N films are first deposited using a graphite target (99.999\%, Lesker) as the carbon source. The growing film is doped with nitrogen using an $\mathrm{Ar} / \mathrm{N}_{2}$ plasma with $10 \% \mathrm{~N}_{2}$ flux of a total of $50 \mathrm{sccm}$. After deposition the resulting films were transported immediately to a tube furnace and annealed under $\mathrm{N}_{2}$ for $1 \mathrm{~h}$. a-C $\mathrm{NH}_{3} 700$ and a-C $\mathrm{NH}_{3} 900$ were prepared by first depositing Nitrogen-free a-C films via DC magnetron sputtering using an Ar plasma ${ }^{[28,52-}$ ${ }^{54]}$ and subsequently treating them with $\mathrm{NH}_{3}$ in a tube furnace according to the following program. First, the temperature of the furnace was ramped to $900{ }^{\circ} \mathrm{C}$ under a $200 \mathrm{~mL} \mathrm{~min}^{-1} \mathrm{~N}_{2}$ flow and held at this temperature for $1 \mathrm{~h}$. For a-C $\mathrm{NH}_{3} 900$ electrodes, the gas composition was changed to $50: 50 \mathrm{NH}_{3} / \mathrm{N}_{2}$ mixture with a total flow of $200 \mathrm{~mL} \mathrm{~min}^{-1}$. After $30 \mathrm{~min}$ of the $\mathrm{NH}_{3}$ treatment the samples were held for a further $1 \mathrm{~h}$ under $200 \mathrm{~mL} \mathrm{~min}^{-1} \mathrm{~N}_{2}$ before ramping down to ambient temperature. For a-C $\mathrm{NH}_{3} 700$ the same treatment was followed as for a-C $\mathrm{NH}_{3} 900$, 
except after annealing under $\mathrm{N}_{2}$ flux at $900{ }^{\circ} \mathrm{C}$ the $\mathrm{NH}_{3}$ treatment was performed at the lower temperature of $700{ }^{\circ} \mathrm{C}$.

Characterization: XPS characterization was performed at a base pressure of $1 \times 10^{-10} \mathrm{mbar}$ in an ultrahigh-vacuum system (Omicron). A monochromatized Al Ka X-ray source (1486.6 eV) was used. Spectra were recorded at a $45^{\circ}$ takeoff angle with an analyzer resolution of $0.5 \mathrm{eV}$. Spectra were baseline-corrected using a Shirley background and fitted with Voigt functions using commercial software (CasaXPS ${ }^{\mathrm{TM}}$ Version 2.3.17); atomic percent compositions were determined by calculating peak area ratios after correction by relative sensitivity factors (C 1s $=1.0, \mathrm{~N} 1 \mathrm{~s}=1.8, \mathrm{O} 1 \mathrm{~s}=2.93)$. Raman spectra were measured in backscattering configuration using a Renishaw 1000 micro-Raman system with an $\mathrm{Ar}^{+}$laser for $488 \mathrm{~nm}$ excitation. A Leica microscope with a $50 \times$ magnification objective and short-focus working distance was used to focus the incident beam. To avoid sample damage, the incident power was kept to $<2 \mathrm{~mW}$. All spectra were baseline-corrected using commercial software prior to analysis (OriginPro 9.1). Roughness measurements were obtained via atomic force microscopy (AFM) as described in the Supporting Information.

Electrochemical studies were carried out using a three-electrode configuration using a Metrohm Autolab AUT50324 potentiostat as previously described. ${ }^{[25]}$ The working electrode was mounted in a static teflon rotating ring disk electrode (RRDE) assembly (Pine Instruments); a Hydroflex hydrogen electrode (Gaskatel) and a graphite rod were used as reference and counter electrodes, respectively, as previously reported. ${ }^{[25]}$ Measurements were carried out in a jacketed electrochemical cell (Pine Instruments) thermostated at $25^{\circ} \mathrm{C}$. Prior to all experiments, the cell was cleaned using piranha solution (CAUTION: piranha solution can be explosive in contact with organics), and rinsed with copious amounts of Millipore water. Cyclic voltammograms (CVs) were acquired over $0.05-1.00 \mathrm{~V}$ vs RHE at a scan rate of $10 \mathrm{mV} \mathrm{s}^{-1}$ and rotation rate of $900 \mathrm{rpm}$ in deaerated $0.1 \mathrm{M} \mathrm{KOH}$ solution $(\mathrm{pH}=13)$. During the $\mathrm{CV}$ the Pt insert of the RRDE 


\section{WILEY-VCH}

was held at a fixed potential of $1.0 \mathrm{~V}$ RHE. A CV in Ar-saturated solution was used to subtract the capacitive background current from the waves obtained in $\mathrm{O}_{2}$-saturated solutions. The number of electrons, $n$, as a function of electrode potential was calculated from RRDE data according to $n=4 I_{D} /\left(I_{D}+I_{R} / N\right)$, where $I_{D}$ indicates the disk current, $I_{R}$ the ring current and $N$ the collection efficiency which was determined to be 0.26 by measurements using ferro/ferricyanide redox couple.

Computational Methods: Density functional theory (DFT) calculations were performed using the dispersion-corrected hybrid functional $\omega \mathrm{B} 97 \mathrm{X}-\mathrm{D},{ }^{[55]}$ as implemented in the Gaussian09 software package. ${ }^{[56]} \mathrm{C}$ and $\mathrm{H}$ atoms were described using the polarized double- $\zeta$ basis set 6$31 \mathrm{G}(\mathrm{d}, \mathrm{p})$, whereas the same basis set including diffuse functions, $6-31+G(d)$, was employed to describe the more electronegative $\mathrm{O}$ atoms. This level of theory has been previously shown to provide satisfactory results in the modelling of similar N-doped carbon nanostructures. ${ }^{[29,57]}$ Geometry optimizations were carried out in implicit water (with dielectric constant, $\varepsilon=$ 78.3553) using the SMD continuum solvation model, ${ }^{[58]}$ and without imposing any symmetry constraints. All stationary points were further confirmed to correspond to energy minima through vibrational frequency analysis. Adsorption Gibbs energies $\left(\Delta \mathrm{G}_{\mathrm{ads}}\right)$ for the different ORR intermediates were calculated at the experimental conditions (i.e. $298 \mathrm{~K}, 1 \mathrm{~atm}$, and pH 14), as detailed in the Supporting Information.

\section{Supporting Information}

Supporting Information is available from the Wiley Online Library or from the author: roughness analysis; additional XPS and Raman spectroscopy data; additional voltammetry data; computational details for the calculation of adsorption Gibbs energies; absolute and relative energies for the reduced and oxidized forms of model clusters; cluster models summarizing all of the active sites explored; adsorption Gibbs energies of all ORR intermediates on all the considered active sites for each model cluster; calculated Gibbs energy diagram at $0.36 \mathrm{~V}_{\mathrm{RHE}}$ at the most active sites on each of the modelled N-doped carbon surface.

\section{Acknowledgements}




\section{WILEY-VCH}

$\mathrm{JAB}$ and EMT contributed equally to this work in the experimental and computational areas, respectively. This publication has emanated from research conducted with the financial support of Science Foundation Ireland under Grant No. 13/CDA/2213. JAB acknowledges support from the Irish Research Council under Grant No. GOIPG/2014/399. This project has received funding from the European Union's Horizon 2020 research and innovation programme under the Marie Skłodowska-Curie grant agreements No. 748968 (FREMAB) and 799175 (HiBriCarbon). The results of this publication reflect only the authors' view and the Commission is not responsible for any use that may be made of the information it contains.

Received: ((will be filled in by the editorial staff))

Revised: ((will be filled in by the editorial staff)) Published online: ((will be filled in by the editorial staff)) 


\section{WILEY-VCH}

Co-presence of pyridinic and graphitic $\mathrm{N}$-sites in metal-free carbon electrodes modulates the binding energy of hydroperoxide/hydroperoxyl intermediates and promotes selectivity towards $4 \mathrm{e}$-reduction in the oxygen reduction reaction.

J. A. Behan, E. Mates-Torres, S. N. Stamatin, C. Domínguez, A. Iannaci, K. Fleischer, Md. K. Hoque, T. S. Perova, M. García-Melchor ${ }^{\mathrm{a}, *}$ and P. E. Colavita ${ }^{\mathrm{a}, *}$

Untangling Cooperative Effects of Pyridinic and Graphitic Nitrogen Sites at Metal-Free N-Doped Carbon Electrocatalysts for the Oxygen Reduction Reaction

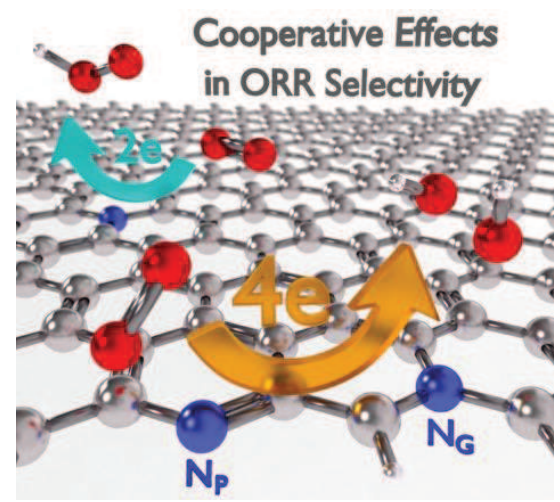




\section{References}

[1] K. Gong, F. Du, Z. Xia, M. Durstock, L. Dai, Science 2009, 323, 760.

[2] L. Qu, Y. Liu, J.-B. Baek, L. Dai, ACS Nano 2010, 4, 1321.

[3] X. Wang, J. S. Lee, Q. Zhu, J. Liu, Y. Wang, S. Dai, Chem. Mater. 2010, 22, 2178.

[4] X. Ge, A. Sumboja, D. Wuu, T. An, B. Li, F. W. T. Goh, T. S. A. Hor, Y. Zong, Z. Liu, ACS Catal. 2015, 5, 4643.

[5] D.-W. Wang, D. Su, Energy Environ. Sci. 2014, 7, 576.

[6] K. N. Wood, R. O'Hayre, S. Pylypenko, Energy Environ. Sci. 2014, 7, 1212.

[7] L. Dai, Curr. Opin. Electrochem. 2017, 4, 18.

[8] G.-L. Chai, Z. Hou, D.-J. Shu, T. Ikeda, K. Terakura, J. Am. Chem. Soc. 2014, 136, 13629.

[9] D. Guo, R. Shibuya, C. Akiba, S. Saji, T. Kondo, J. Nakamura, Science 2016, 351, 361.

[10] G. R. S. Iyer, J. Wang, G. Wells, M. P. Bradley, F. Borondics, Nanoscale 2015, 7, 2289.

[11] F. Joucken, Y. Tison, J. Lagoute, J. Dumont, D. Cabosart, B. Zheng, V. Repain, C. Chacon, Y. Girard, A. R. Botello-Méndez, S. Rousset, R. Sporken, J.-C. Charlier, L. Henrard, Phys. Rev. B 2012, 85, 161408.

[12] J. P. McClure, J. D. Thornton, R. Jiang, D. Chu, J. J. Cuomo, P. S. Fedkiw, J. Electrochem. Soc. 2012, 159, F733.

[13] T. Sharifi, G. Hu, X. Jia, T. Wågberg, ACS Nano 2012, 6, 8904.

[14] K.-H. Wu, D.-W. Wang, X. Zong, B. Zhang, Y. Liu, I. R. Gentle, D.-S. Su, J. Mater. Chem. A 2017, 5, 3239.

[15] Y. Zhu, Y. Lin, B. Zhang, J. Rong, B. Zong, D. S. Su, ChemCatChem 2015, 7, 2840.

[16] C. H. Choi, H.-K. Lim, M. W. Chung, J. C. Park, H. Shin, H. Kim, S. I. Woo, J. Am. Chem. Soc. 2014, 136, 9070.

[17] J. Chen, X. Wang, X. Cui, G. Yang, W. Zheng, Chem. Commun. 2014, 50, 557.

[18] L. Lai, J. R. Potts, D. Zhan, L. Wang, C. K. Poh, C. Tang, H. Gong, Z. Shen, J. Lin, R. S. Ruoff, Energy Environ. Sci. 2012, 5, 7936.

[19] Z. Luo, S. Lim, Z. Tian, J. Shang, L. Lai, B. MacDonald, C. Fu, Z. Shen, T. Yu, J. Lin, J. Mater. Chem. 2011, 21, 8038. 


\section{WILEY-VCH}

[20] C. Tang, Q. Zhang, Adv. Mater. (Weinheim, Ger.) 2017, 29, 1604103.

[21] Q. Li, S. Zhang, L. Dai, L.-s. Li, J. Am. Chem. Soc. 2012, 134, 18932.

[22] C. Domìnguez, J. A. Behan, P. E. Colavita, in Nanocarbon Electrochemistry, (Eds: N. Yang, G. Zhao, J. S. Foord), John Wiley \& Sons, Ltd, Chichester 2019, in press.

[23] M. Favaro, S. Agnoli, L. Perini, C. Durante, A. Gennaro, G. Granozzi, Phys. Chem. Chem. Phys. 2013, 15, 2923.

[24] M. Favaro, L. Perini, S. Agnoli, C. Durante, G. Granozzi, A. Gennaro, Electrochim. Acta 2013, 88, 477.

[25] J. A. Behan, A. Iannaci, C. Domínguez, S. N. Stamatin, M. K. Hoque, J. M. Vasconcelos, T. S. Perova, P. E. Colavita, Carbon 2019, 148, 224.

[26] B. B. Blizanac, P. N. Ross, N. M. Markovic, Electrochim. Acta 2007, 52, 2264.

[27] N. Ramaswamy, S. Mukerjee, J. Phys. Chem. C 2011, 115, 18015.

[28] J. A. Behan, S. N. Stamatin, M. K. Hoque, G. Ciapetti, F. Zen, L. Esteban-Tejeda, P. E. Colavita, J. Phys. Chem. C 2017, 121, 6596.

[29] J. A. Behan, M. K. Hoque, S. N. Stamatin, T. S. Perova, L. Vilella-Arribas, M. GarciaMelchor, P. E. Colavita, J. Phys. Chem. C 2018, 122, 20763.

[30] J. Y. Chen, X. Wang, X. Q. Cui, G. M. Yang, W. T. Zheng, Catal. Commun. 2014, 46, 161.

[31] J. T. Titantah, D. Lamoen, Diamond Relat. Mater. 2007, 16, 581.

[32] L. D. Jiang, A. G. Fitzgerald, M. J. Rose, Appl. Surf. Sci. 2001, 181, 331.

[33] A. C. Ferrari, S. E. Rodil, J. Robertson, Phys. Rev. B 2003, 67, 155306.

[34] A. C. Ferrari, J. Robertson, Phys. Rev. B 2001, 64, 075414.

[35] A. C. Ferrari, J. Robertson, Phys. Rev. B 2000, 61, 14095.

[36] N. McEvoy, N. Peltekis, S. Kumar, E. Rezvani, H. Nolan, G. P. Keeley, W. J. Blau, G. S. Duesberg, Carbon 2012, 50, 1216.

[37] N. Laidani, L. Guzman, A. Miotello, R. S. Brusa, G. P. Karwasz, A. Zecca, C. Bottani, J. Perrière, Nucl. Instrum. Methods Phys. Res., Sect. B 1997, 122, 553.

[38] L. G. Cançado, K. Takai, T. Enoki, M. Endo, Y. A. Kim, H. Mizusaki, A. Jorio, L. N. Coelho, R. Magalhães-Paniago, M. A. Pimenta, Appl. Phys. Lett. 2006, 88, 163106.

[39] Y. Qiu, J. Yu, T. Shi, X. Zhou, X. Bai, J. Y. Huang, J. Power Sources 2011, 196, 9862.

[40] S. N. Stamatin, I. Hussainova, R. Ivanov, P. E. Colavita, ACS Catal. 2016, 6, 5215. 
[41] D. Kan, Y. Orikasa, K. Nitta, H. Tanida, R. Kurosaki, T. Nishimura, T. Sasaki, H. Guo, Y. Ozaki, Y. Uchimoto, Y. Shimakawa, J. Phys. Chem. C 2016, 120, 6006.

[42] K. J. J. Mayrhofer, D. Strmcnik, B. B. Blizanac, V. Stamenkovic, M. Arenz, N. M. Markovic, Electrochim. Acta 2008, 53, 3181.

[43] S. Fletcher, J. Solid State Electrochem. 2009, 13, 537.

[44] A. Holewinski, S. Linic, J. Electrochem. Soc. 2012, 159, H864.

[45] J. P. Hoare, in Standard Potentials in Aqueous Solution, (Eds: A. J. Bard, R. Parsons, J. Jordan), 1985, 49.

[46] I. Katsounaros, W. B. Schneider, J. C. Meier, U. Benedikt, P. U. Biedermann, A. Cuesta, A. A. Auer, K. J. J. Mayrhofer, Phys. Chem. Chem. Phys. 2013, 15, 8058.

[47] N. Ramaswamy, S. Mukerjee, Advances in Physical Chemistry 2012, 2012, 17.

[48] A. J. Bard, R. Parsons, J. Jordan, Standard Potentials in Aqueous Solution, Marcel Dekker, Inc., 1985.

[49] N. Ramaswamy, U. Tylus, Q. Jia, S. Mukerjee, J. Am. Chem. Soc. 2013, 135, 15443.

[50] H. H. Yang, R. L. McCreery, J. Electrochem. Soc. 2000, 147, 3420.

[51] B. H. Bielski, A. O. Allen, J. Phys. Chem. 1977, 81, 1048.

[52] M. K. Hoque, J. A. Behan, S. N. Stamatin, F. Zen, T. S. Perova, P. E. Colavita, RSC Advances 2019, 9, 4063.

[53] D. M. Murphy, R. J. Cullen, D. R. Jayasundara, R. L. Doyle, M. E. Lyons, P. E. Colavita, J. Phys. Chem. C 2013, 117, 22768.

[54] F. Zen, M. D. Angione, J. A. Behan, R. J. Cullen, T. Duff, J. M. Vasconcelos, E. M. Scanlan, P. E. Colavita, Sci. Rep. 2016, 6, 24840.

[55] J.-D. Chai, M. Head-Gordon, Phys. Chem. Chem. Phys. 2008, 10, 6615.

[56] M. J. Frisch, G. W. Trucks, H. B. Schlegel, G. E. Scuseria, M. A. Robb, J. R. Cheeseman, G. Scalmani, V. Barone, B. Mennucci, G. A. Petersson, H. Nakatsuji, M. Caricato, X. Li, H. P. Hratchian, A. F. Izmaylov, J. Bloino, G. Zheng, J. L. Sonnenberg, M. Hada, M. Ehara, K. Toyota, R. Fukuda, J. Hasegawa, M. Ishida, T. Nakajima, Y. Honda, O. Kitao, H. Nakai, T. Vreven, J. A. Montgomery, J. E. Peralta, F. Ogliaro, M. Bearpark, J. J. Heyd, E. Brothers, K. N. Kudin, V. N. Staroverov, R. Kobayashi, J. Normand, K. Raghavachari, A. Rendell, J. C. Burant, S. S. Iyengar, J. Tomasi, M. Cossi, N. Rega, J. M. Millam, M. Klene, J. E. Knox, J. B. Cross, V. Bakken, C. Adamo, J. Jaramillo, R. Gomperts, R. E. Stratmann, O. Yazyev, A. J. Austin, R. Cammi, C. Pomelli, J. W. Ochterski, R. L. Martin, K. Morokuma, V. G. Zakrzewski, G. A. Voth, P. Salvador, J. J. Dannenberg, S. Dapprich, A. D. Daniels, Farkas, J. B. Foresman, J. V. Ortiz, J. Cioslowski, D. J. Fox, Gaussian Inc. , Wallingford CT 2009. 


\section{WILEY-VCH}

[57] J. A. Behan, F. Grajkowski, D. R. Jayasundara, L. Vilella-Arribas, M. GarcíaMelchor, P. E. Colavita, Electrochim. Acta 2019, 304, 221.

[58] A. V. Marenich, C. J. Cramer, D. G. Truhlar, J. Phys. Chem. B 2009, 113, 6378. 